\title{
ANALYSIS OF POSSIBILITIES OF LOW-COST PHOTOGRAMMETRY FOR INTERIOR MAPPING
}

\author{
A. Dlesk ${ }^{1, *}, \mathrm{~K}$. Vach $^{2}$, P. Holubec ${ }^{3}$ \\ ${ }^{1}$ Department of Geomatics, CTU in Prague - adam.dlesk@gmail.com \\ ${ }^{2}$ EuroGV s.r.o. - vach@eurogv.cz \\ ${ }^{3}$ EuroGV s.r.o. - holubec@eurogv.cz
}

Commission V, WG V/7 \& Commission IV, WG IV/6

KEY WORDS: Photogrammetry, Interior mapping, Exposure, SfM, BIM, fisheye lens

\begin{abstract}
:
This paper shows the possibilities of using low-cost photogrammetry for interior mapping as a tool to gather fast and accurate data for 3D modelling and BIM. To create a 3D model of a building interior with a high level of detail requires techniques such as laser scanning and photogrammetry. In the case of photogrammetry, it is possible to use standard cameras and SfM software to create an accurate point cloud which can be used for 3D modelling and then for BIM. The images captured indoor are often captured under lower light conditions. Using different exposure during capturing of images of building interior was tested. Frequent plain walls of a building interior cause that the images are usually lack of any features and their photogrammetric processing is getting much more difficult. In some cases, results of photogrammetric processing are poor and inaccurate. In this paper, an experiment of creating a 3D model of a building interior using photogrammetric processing of images was carried out. For this experiment digital camera with two different lenses (16 mm lens and fisheye lens) was used. For photogrammetric processing were chosen different software. All the results were compared to each other and to the laser scanning data of the interior. At the end of the paper, the discussion of the advantages and disadvantages of the shown method has been made.
\end{abstract}

\section{INTRODUCTION}

3D modelling of already constructed objects is getting to be more and more important due to the increasing number of inquiries for Building Information Modelling (BIM). Laser scanning is a sufficient and reliable tool for obtaining point cloud for following 3D modelling. In this paper, Leica BLK 360 laser scanner was used, because it is a device which offers suitable and reliable results (Luhman, 2019). Photogrammetry, mainly SfM (Structure from Motion), is an alternative to laser scanning in point cloud generation. In the case of interior mapping, the problem with low or non-textured parts of object e.g. plain walls and possibly low light conditions makes photogrammetric processing much more difficult. In this paper, an experiment of interior mapping has been carried out. As a test object a room of a family house has been chosen. The room with plain white walls and few glossy objects which are considered as a negative factor for SfM processing was chosen on purpose. The room was surveyed with a total station and with the laser scanner Leica BLK 360. For photogrammetric processing, images were captured by mirrorless camera SONY alpha a6000. It is possible to consider a room as a narrow object, where fisheye lens for imaging is suitable to use (Perfetti, 2017) (Marčiš, 2016). The captured images were processed in SfM software. Agisoft Photoscan has been chosen as a commercial alternative based on SfM and photogrammetric software MicMac has been chosen as an opensource low-cost alternative, also based on SfM. The ability of 3D modelling from point cloud created with photogrammetric processing based on SfM was tested. Parameters of the final 3D model were compared to the measurement with the total station and to the point cloud obtained by the laser scanner. At the end of the paper, discussion about the advantages and disadvantages of tested methods including factors as accuracy, user-friendliness, the time cost is part of the paper.

\subsection{Test object}

As a test object, a room of a family house has been chosen. The room was chosen on purpose to simulate difficult conditions. The walls of the room are white and plain without any texture. There is a glossy wardrobe, glossy table, a large mirror in the room, glass door and lots of high flowers set in the room corners. All these factors potentially make photogrammetric processing based on SfM much more difficult. The room has also three windows, one door, a wooden floor and a plain ceiling with chandeliers made from metal.

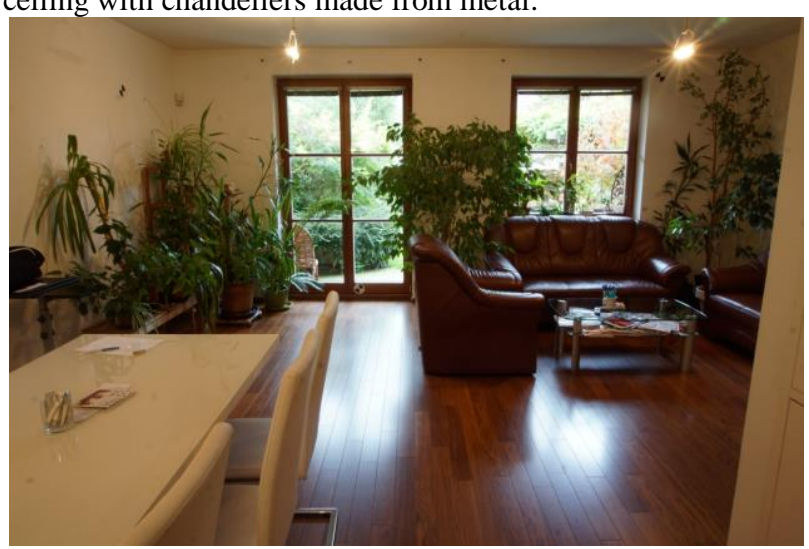

Figure 1. Test room

\footnotetext{
* Corresponding author
} 


\section{SURVEYING OF THE TEST OBJECT}

\subsection{Camera, lenses and laser scanner}

For capturing images has been chosen digital mirrorless camera SONY alpha a6000 with original lens $(16 \mathrm{~mm}$ focal length) and Samyang fisheye lens (8 $\mathrm{mm}$ focal length) suitable for imaging of narrow places as this room could be considered. For laser scanning Leica BLK 360 was used. Leica BLK 360 is a relatively small and easy-to-use laser scanner that is operated by a tablet connected via Wi-Fi to the laser scanner.

\subsection{Surveying}

First of all, coded targets and black-and-white targets were equally distributed around the room. There were used 10 12-bit coded targets, 5 used as control points and 5 used as check points. 8 black-and-white targets were placed for laser scanning. Those targets were measured with total station Topcon DS Series from a single station. After measuring the targets, corners of the room, the height of the floor, the height of the ceiling and windows were measured as well. Then the room has been surveyed with laser scanner Leica BLK 360 . Capturing of images with $16 \mathrm{~mm}$ lens has been carried out during midday daylight without artificial lighting. The capturing scenario was set to follow the official recommendation of Agisoft Photoscan manual but because of all the furniture and other objects, it was not ideally possible. For each window, extra images were captured. In total, 90 images have been captured. Capturing of images with fisheye lens were carried out immediately after. Due to the wide field of view was not necessary to capture too many images. 35 images have been captured with fisheye lens. The idea was to not capture too many images to make imaging as fast as possible and to cut the time cost down. For both groups of images (16 $\mathrm{mm}$ lens and fisheye lens), the manual focusing was fixed and f-number was set high to obtain a large depth of field. Even though the capturing of images has been carried out during the midday daylight, the room was relatively dark. This has been reduced by increasing exposure time. Because of that, tripod for the camera must have been used and capturing the scene took then longer.

\section{PHOTOGRAMMETRIC PROCESSING}

For photogrammetric processing was used software based on SfM. There were chosen two alternatives - commercial software and opensource. In each software two groups of images (16mm original lens and fisheye) have been processed separately. The goal of the processing was to create a dense accurate point cloud that could be then used for proper and easy $3 \mathrm{D}$ modelling of the room.

\subsection{Processing in Agisoft Photoscan}

As a commercial alternative of photogrammetric software based on SfM, Agisoft Photoscan (in version 1.4.3.6488) has been used. Following workflow of processing images was used.

1. Align Photos

2. Detecting Markers

3. Optimize Camera

4. Build Dense Cloud

Using Align Photos, the relative orientation of all the images was computed. All the images of both groups were co- registered. In total, 61855 tie points were computed for a group of photos captured with $16 \mathrm{~mm}$ lens and 12263 tie points were computed for group of images captured with fisheye lens. The lower number of tie points computed from fisheye lens images could be caused by lower number of images. Most of the tie points were on furniture in the room, on flowers and on the floor. Some of them were even on metal chandeliers.

\begin{tabular}{|c|c|c|c|}
\hline & $\begin{array}{c}\text { Co-registered } \\
\text { images }\end{array}$ & $\begin{array}{c}\text { Num. of } \\
\text { tie Points }\end{array}$ & $\begin{array}{c}\text { Num. of } \\
\text { points in } \\
\text { point cloud }\end{array}$ \\
\hline $16 \mathrm{~mm}$ lens & $90 / 90$ & 61855 & 7369776 \\
\hline Fisheye lens & $35 / 35$ & 12263 & 3276619 \\
\hline
\end{tabular}

Table 1. Results of processing in Agisoft Photoscan.

After computing relative orientation, photogrammetric targets were automatically detected on images and 5 of them were used for absolute orientation and bundle adjustment of the model. 5 of them were left for an accuracy check. Total RMSE of control points was $0,002 \mathrm{~m}$ for group of images captured with $16 \mathrm{~mm}$ lens and $0,001 \mathrm{~m}$ for group of images captured with fisheye lens. Total RMSE of check points was $0,006 \mathrm{~m}$ for group of images captured with $16 \mathrm{~mm}$ lens and $0,002 \mathrm{~m}$ for group of images captured with fisheye lens.

\begin{tabular}{|c|c|c|c|c|}
\hline & $\begin{array}{c}\text { X Error } \\
{[\mathrm{m}]}\end{array}$ & $\begin{array}{c}\text { Y Error } \\
{[\mathrm{m}]}\end{array}$ & $\begin{array}{c}\text { Z Error } \\
{[\mathrm{m}]}\end{array}$ & Total $[\mathrm{m}]$ \\
\hline $16 \mathrm{~mm}$ lens & 0,002 & 0,001 & 0,001 & 0,002 \\
\hline Fisheye lens & 0,001 & 0,001 & 0,001 & 0,001 \\
\hline
\end{tabular}

Table 2. Control points - RMSE values.

\begin{tabular}{|c|c|c|c|c|}
\hline & $\begin{array}{c}\text { X Error } \\
{[\mathrm{m}]}\end{array}$ & $\begin{array}{c}\text { Y Error } \\
{[\mathrm{m}]}\end{array}$ & $\begin{array}{c}\text { Z Error } \\
{[\mathrm{m}]}\end{array}$ & Total $[\mathrm{m}]$ \\
\hline $16 \mathrm{~mm}$ lens & 0,002 & 0,003 & 0,004 & 0,006 \\
\hline Fisheye lens & 0,002 & 0,001 & 0,001 & 0,002 \\
\hline
\end{tabular}

Table 3. Check points - RMSE values.

Then, Build Dense Cloud tool computed for both groups (16 $\mathrm{mm}$ lens and fisheye lens) quite dense point cloud. For group of images captured with $16 \mathrm{~mm}$ focal length, point cloud with 7369776 points was created. Point cloud created from group of images captured with fisheye lens contained 3276912 points. Even in parts with almost no texture e.g. plain walls and ceiling, many points were created at both point clouds. It was obvious that point clouds contained at those parts a lot of noise, but the number of points seemed enough to have the possibility to create a proper 3D model. Parts with texture e.g. floor, furniture, flowers and windows contained high number of points. At windows, window frames were easy to detect on both point clouds.

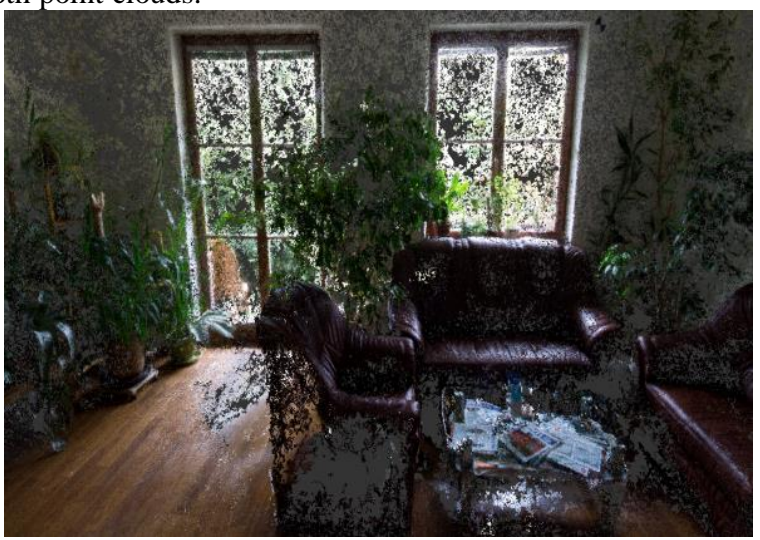

Figure 2. Point cloud created in Agisoft Photoscan from images captured with fisheye lens 


\subsection{Processing in MicMac}

MicMac is a free and opensource photogrammetric tool based on SfM and developed at the National Institute of Geographic and Forestry Information (IGN) and ENSG (French national school for geographic sciences). MicMac is controlled through the command line and is suitable for different kinds of application. For the processing in this paper, MicMac v1.0.beta13 was used. Photogrammetric workflow for creating point cloud is:

$\begin{array}{ll}\text { 1. } & \text { Tapioca } \\ \text { 2. } & \text { Tapas } \\ \text { 3. } & \text { GCPBascule } \\ \text { 4. } & \text { Campari } \\ \text { 5. } & \text { C3DC }\end{array}$

By using commands Tapioca and Tapas, the relative orientation of images was computed. All the images of both groups were co-registered. Number of tie points was much higher compared to the tie points from processing in Agisoft Photoscan. Most of the tie points represented objects like flowers and wooden furniture. Fewer tie points were on room floor.

\begin{tabular}{|c|c|c|c|}
\hline & $\begin{array}{c}\text { Coregistered } \\
\text { images }\end{array}$ & $\begin{array}{c}\text { Num. of } \\
\text { tie Points }\end{array}$ & $\begin{array}{c}\text { Num. of } \\
\text { points in } \\
\text { point cloud } \\
\text { (by C3DC } \\
\text { QuickMac) }\end{array}$ \\
\hline $16 \mathrm{~mm}$ lens & $90 / 90$ & 230073 & 459650 \\
\hline Fisheye lens & $35 / 35$ & 59289 & 77850 \\
\hline
\end{tabular}

Table 4. Results of processing in MicMac.

Absolute orientation was computed after manual marking of targets by GCPBascule and Campari commands. 5 of the points were used as control points and total RMSE of control points after absolute orientation was $0,002 \mathrm{~m}$ for group of images captured with $16 \mathrm{~mm}$ lens and $0,001 \mathrm{~m}$ for group of images captured with fisheye lens. After commands GCPBascule and Campari, 5 checked points were measured, and the coordinates were compared to the coordinates measured with the total station. For group of images captured with $16 \mathrm{~mm}$ lens total RMSE of the check points was $0,003 \mathrm{~m}$ and $0,002 \mathrm{~m}$ for the group of images captured with fisheye lens.

\begin{tabular}{|c|c|c|c|c|}
\hline & $\begin{array}{c}\text { X Error } \\
{[\mathrm{m}]}\end{array}$ & $\begin{array}{c}\text { Y Error } \\
{[\mathrm{m}]}\end{array}$ & $\begin{array}{c}\text { Z Error } \\
{[\mathrm{m}]}\end{array}$ & Total $[\mathrm{m}]$ \\
\hline $16 \mathrm{~mm}$ lens & 0,001 & 0,001 & 0,001 & 0,002 \\
\hline Fisheye lens & 0,001 & 0,001 & 0,001 & 0,001 \\
\hline
\end{tabular}

Table 5. Control points - RMSE values.

\begin{tabular}{|c|c|c|c|c|}
\hline & $\begin{array}{c}\text { X Error } \\
{[\mathrm{m}]}\end{array}$ & $\begin{array}{c}\text { Y Error } \\
{[\mathrm{m}]}\end{array}$ & $\begin{array}{c}\text { Z Error } \\
{[\mathrm{m}]}\end{array}$ & Total $[\mathrm{m}]$ \\
\hline $16 \mathrm{~mm}$ lens & 0,002 & 0,002 & 0,001 & 0,003 \\
\hline Fisheye lens & 0,002 & 0,002 & 0,001 & 0,002 \\
\hline
\end{tabular}

Table 6. Check points - RMSE values.

Point cloud was created using command C3DC. The resulted point clouds for both sets of images were very thin and for 3D modelling obviously unusable. C3DC command was used with different types of arguments. Argument Statue which uses strictly epipolar mode provided the highest number of points (more than 1 million) in the point cloud but compared to the point cloud from Agisoft Photoscan it is a very low number. At parts of the room such as white walls and ceiling, almost none of the points were created. At parts as window frames, the point cloud was very thin and even with almost no points on the floor. C3DC command with QuickMac argument provided fewer points but better distributed around the test room. Even these point clouds were obviously unusable for further modelling. Compared to point cloud made in Agisoft Photoscan, where the floor represented enough number of points the result of C3DC command was very poor. Even though accuracy check by 5 check points showed accurate relative orientation which could be usable for discrete points measuring.

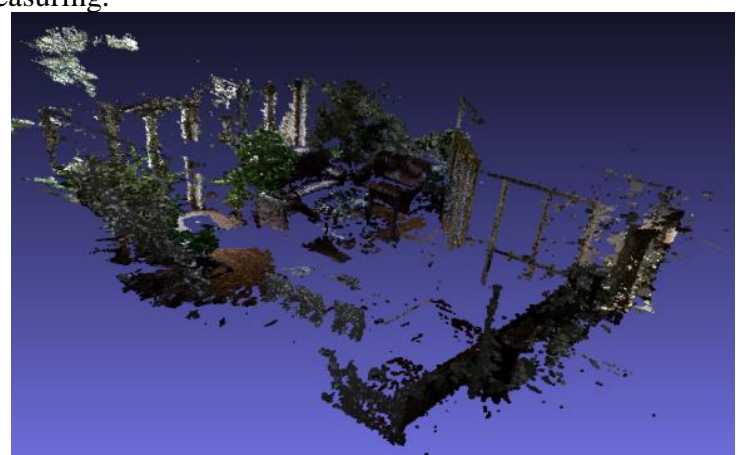

Figure 3. Point cloud created by C3DC QuickMac in MicMac.

\section{RESULTS}

The results of photogrammetric processing in Agisoft Photoscan were point clouds that were analysed if it is possible to use the point clouds for following 3D modelling and if the method is comparable to laser scanning with Leica BLK 360. The resulted point clouds from photogrammetric processing in MicMac were not sufficient to use for modelling of the room and were not in the following experiment used.

\subsection{Comparison to ideal planes}

3D model of the room was created from points measured by the total station. The walls, floor and ceiling were considered as ideal planes and the point clouds from photogrammetric processing were compared to the 3D model in Cloud Compare software. First of all, point clouds were manually filtered into three parts. To the first part belonged points which obviously represented walls of the room. The second part belonged to the points which represented the floor and points of the third part represented the ceiling of the room.

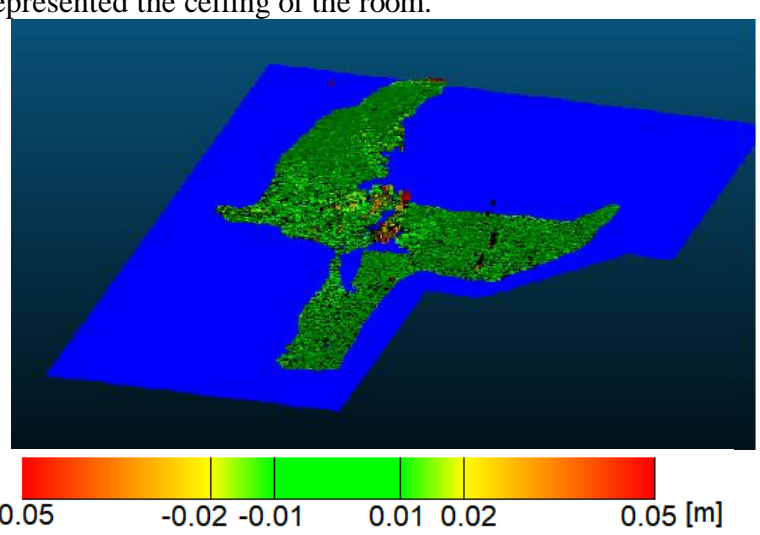

Figure 4. Example of comparison between point cloud and 3D model of the floor. 
The following graphs show that the average value of the set of distances in the parts of the floor and walls is under $0.01 \mathrm{~m}$ from the model of ideal planes for both group of images. In the case of point cloud which represents wall, standard deviation of set of distances is much higher compared to the standard deviation of distances computed from point cloud which represents floor. The point cloud of the ceiling is much noisier and in this case, point cloud created from images captured with fisheye lens in comparison to the model of ceiling has lower mean and lower standard deviation then point cloud created from images captured with $16 \mathrm{~mm}$ lens in comparison to the model of the ceiling.

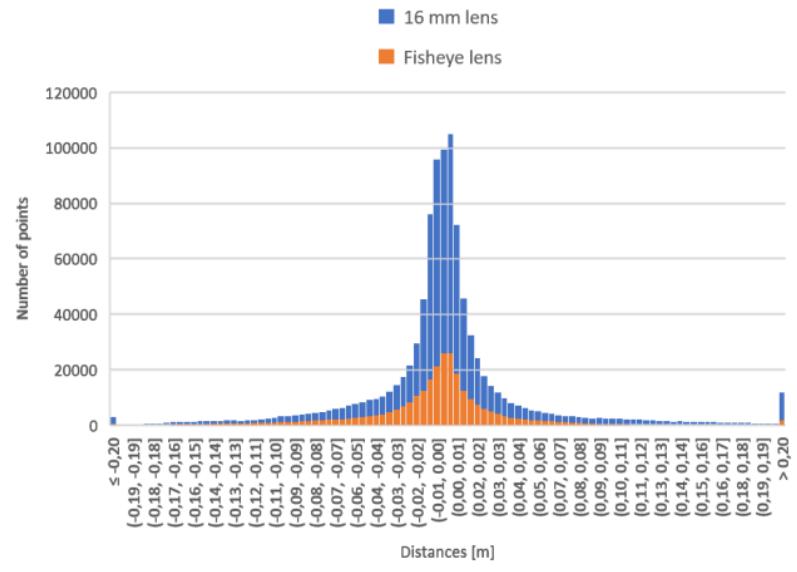

Figure 5. Histogram of set of distances for walls

\begin{tabular}{|c|c|c|}
\hline & Mean $[\mathrm{m}]$ & Standard deviation $[\mathrm{m}]$ \\
\hline 16 mm lens & $-0,001$ & 0,056 \\
\hline Fisheye lens & $-0,007$ & 0,057 \\
\hline
\end{tabular}

Table 7. Statistical values of set of distances for walls.

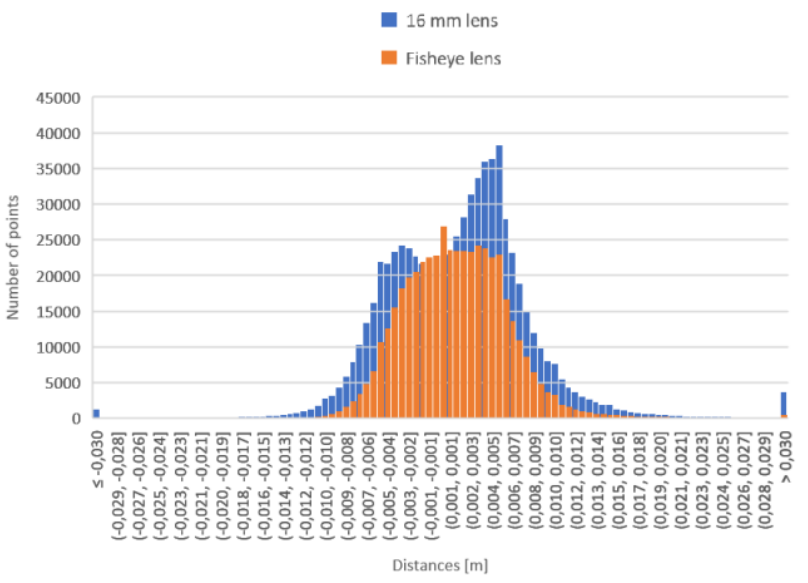

Figure 6. Histogram of set of distances for floor.

\begin{tabular}{|c|c|c|}
\hline & Mean $[\mathrm{m}]$ & Standard deviation $[\mathrm{m}]$ \\
\hline $16 \mathrm{~mm}$ lens & 0,002 & 0,007 \\
\hline Fisheye lens & 0,001 & 0,006 \\
\hline
\end{tabular}

Table 8. Statistical values of set of distances for floor.

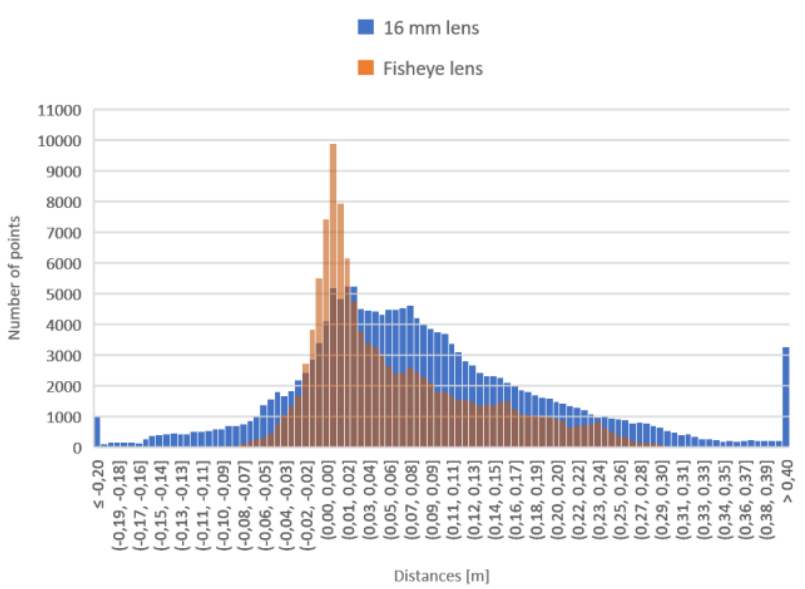

Figure 7. Histogram of set of distances for ceiling.

\begin{tabular}{|c|c|c|}
\hline & Mean [m] & Standard deviation [m] \\
\hline 16 mm lens & 0,084 & 0,119 \\
\hline Fisheye lens & 0,059 & 0,075 \\
\hline
\end{tabular}

Table 9. Statistical values of set of distances for ceiling.

\subsection{Test of modelling}

Resulted point clouds from photogrammetric processing from Agisoft Photoscan were tested in a matter of possibility of using these point clouds for 3D modelling. Point cloud created by laser scanner Leica BLK 360 was taken into account as well. A slice of the point clouds was created. The slice was $0.20 \mathrm{~m}$ thick and cut the point clouds horizontally. If the slice was thinner it was not possible to detect the position of the wall properly on point cloud created photogrammetrically. Point cloud created with BLK 360 could be investigated with a thinner slice. For both cases (16 mm lens and fisheye lens) was not a problem to determine the course of the wall. Using both point clouds created in Agisoft Photoscan and point cloud created with laser scanner Leica BLK 360 were created 3D models. Comparison of parameters of the model has been made. Among the tested parameters were lengths of chosen walls, width of all three windows and height of the ceiling. As reference values were taken values from measurement with the total station which were used also for modelling the ideal planes.

\begin{tabular}{|c|c|c|c|c|}
\hline & $\begin{array}{c}\text { Total } \\
\text { station } \\
{[\mathrm{m}]}\end{array}$ & $\begin{array}{c}\text { BLK } \\
360 \\
{[\mathrm{~m}]}\end{array}$ & $\begin{array}{c}16 \mathrm{~mm} \\
\text { lens } \\
{[\mathrm{m}]}\end{array}$ & $\begin{array}{c}\text { Fisheye } \\
\text { lens } \\
{[\mathrm{m}]}\end{array}$ \\
\hline Length n. 1 & 5,985 & 5,980 & 6,000 & 5,959 \\
\hline Length n. 2 & 3,079 & 3,078 & 3,076 & 3,032 \\
\hline Length n. 3 & 0,544 & 0,538 & 0,536 & 0,565 \\
\hline Length n. 4 & 0,647 & 0,657 & 0,655 & 0,643 \\
\hline Length n. 5 & 3,523 & 3,515 & 3,524 & 3,581 \\
\hline Length n. 6 & 7,129 & 7,128 & 7,130 & 7,168 \\
\hline Width of window n.1 & 1,474 & 1,473 & 1,451 & 1,454 \\
\hline Width of window n.2 & 1,461 & 1,458 & 1,449 & 1,440 \\
\hline Width of window n.3 & 0,861 & 0,864 & 0,840 & 0,777 \\
\hline Height of ceiling & 2,700 & 2,709 & 2,703 & 2,694 \\
\hline Average difference & $\mathrm{x}$ & 0,005 & 0,010 & 0,033 \\
\hline Maximal difference & $\mathrm{x}$ & 0,010 & 0,023 & 0,084 \\
\hline
\end{tabular}

Table 10. Comparison of parameters of 3D models of the room created from point clouds and measurement with total station. 
The average difference was computed as a mean value of set of absolute values of differences. The comparison showed that parameters of created model from point cloud by Leica BLK 360 are in average difference $0,005 \mathrm{~m}$. The highest difference $0,009 \mathrm{~m}$ is in length number 4 . The comparison showed a difference between modelling from point cloud created by photogrammetric processing of images captured with $16 \mathrm{~mm}$ lens and fisheye lens. Lower differences were shown in parameters at model created from point cloud created from 16 $\mathrm{mm}$ lens images. Average difference was $0,010 \mathrm{~m}$. The highest difference was $0,023 \mathrm{~m}$. Parameters of model created from fisheye lens images differ more. The average difference was $0,033 \mathrm{~m}$ and even in width of one window the difference was $0,084 \mathrm{~m}$ which shows unreliability.

\section{CONCLUSION}

Interior mapping for 3D modelling and BIM could be carried out by laser scanner. Photogrammetry and SfM could be an alternative for laser scanning in terms of interior mapping. In interiors of buildings there are many factors that can negatively affect photogrammetric processing. One of those factors can be lack of texture on plain walls of interior or lots of glossy and shiny objects. Also, lighting condition is usually darker than outside of the building and proper exposure must be set for every room of building interior which takes time. Capturing of images on tripod with long exposure also increases the time of surveying the interior. This paper showed if photogrammetry is a comparable alternative to laser scanning for interior mapping under unpleasant mentioned conditions. For testing, the room of a family house has been chosen. The room was measured by the total station and was surveyed also with laser scanner Leica 360 BLK. Images were captured by the mirrorless camera with two different lenses (16 mm original lens and fisheye lens). The images were processed in two different software. Agisoft Photoscan was chosen as a commercial alternative and MicMac was chosen as an opensource alternative. Relative orientation of two groups of images (16mm and fisheye) was successful and accuracy check on checkpoints showed that the orientation is relatively accurate. Total RMSE of check points were not higher than $0,006 \mathrm{~m}$. This shows that it is possible to expect good results during discrete measuring of points. For faster 3D modelling of the room it is necessary to compute point cloud. Point clouds created with MicMac were very thin and it was obvious at first sight that it is not possible to create 3D model from those point clouds. On the other hand, commercial software Agisoft Photoscan created relatively dense point cloud from both sets of images (16 mm and fisheye). Different parts of the point clouds (walls, floor, ceiling) were compared to the 3D model composed of ideal planes. At the part of floor, both point clouds had the lowest standard deviation. The part of ceiling was the most inaccurate and contained a lot of noise. At the part of walls, means of all distances were under $0,01 \mathrm{~m}$ but the standard deviations were under $0,06 \mathrm{~m}$. Both point clouds (16 $\mathrm{mm}$ and fisheye) were tested with point cloud created by Leica BLK 360 if it is possible to create accurately 3D model based on them. The test was carried out by testing on chosen parameters of the resulted 3D model. Different lengths, widths and high were tested and compared to the measurement by total station. Parameters from model created from point cloud by Leica BLK scanner were most accurate to the model from measurement by total station. The average value of absolute values of differences was $0,005 \mathrm{~m}$ and the highest difference was $0,01 \mathrm{~m}$. 3D model created from images captured by $16 \mathrm{~mm}$ lens was more accurate to the 3D model created from measurement by total station then 3D model from point cloud created by fisheye images. The average value of absolute values of differences was $0,010 \mathrm{~m}$ and the highest difference was 0,023 but the parameters of 3D model from point cloud created from fisheye images differed in average $0,033 \mathrm{~m}$ and the highest difference was $0,084 \mathrm{~m}$. This could be also caused by the lower number of images captured with fisheye lens. Even though differences of parameters of 3D model created from point cloud from images by $16 \mathrm{~mm}$ lens were under certain tolerance, the testing showed the unreliability of the method. Also, the time cost should be considered. Time for capturing of the images is comparable to the time of the scanning with Leica BLK 360 . The scanning itself with Leica BLK 360 is user-friendly, the scanner is light and operated just with one button. The resulted point cloud of laser scanner is denser and more reliable for 3D modelling. Time for photogrammetric processing is much higher than for processing of laser scanning data. The point clouds from photogrammetric processing were noisy in parts with lack of texture and creating 3D model was more difficult which increased time cost as well.

\section{ACKNOWLEDGEMENTS}

This project was supported by grant of the Grant Agency of the Czech Technical University in Prague, grant No. SGS19/048/OHK1/1T/11. This project is a part of internal research of EuroGV s.r.o. company.

\section{REFERENCES}

Luhmann, T.; Robson, S.; Kyle, S.; Harley, I., 2007. Close range photogrammetry. Wiley.

Luhmann, T., Chizhova M., Gorkovchuk D., Hastedt H., Chachava N., Lekveishvili N., 2019: Combination of terrestrial laserscanning, UAV and close-range photogrammetry for 3D reconstruction of complex churches in Georgia. Int. Arch. Photogramm. Remote Sens. Spatial Inf. Sci., XLII-2/W11, 753761. doi.org/10.5194/isprs-archives-XLII-2-W11-753-2019.

Marčiš, M., Barták P., Valaška D., Fraštia M., Trhan O. 2016: Use of image based modelling for documentation of intricately shaped objects. Int. Arch. Photogramm. Remote Sens. Spatial Inf. Sci., XLI-B5, 327-334. doi.org/10.5194/isprs-archivesXLI-B5-327-2016.

Perfetti, L., Polari C., Fassi F., 2017: Fisheye photogrammetry: tests and methodologies for the survey of narrow spaces. Int Arch. Photogramm. Remote Sens. Spatial Inf. Sci., XLII-2/W3, 573-580. doi.org/10.5194/isprs-archives-XLII-2-W3-573-2017.

Rupnik, E., Daakir, M., Deseilligny, M. P., 2017: MicMac - a free, open-source solution for photogrammetry. Open Geospatial Data, Software and Standards 2:14, 1-9. 